\title{
Preparation of poly(ethylene terephthalate)/layered double hydroxide nanocomposites by in-situ polymerization and their thermal property
}

\author{
W. Cui, Q. Jiao* , Y. Zhao, H. Li, H. Liu, M. Zhou \\ School of Chemical Engineering and the Environment, Beijing Institute of Technology, 100081 Beijing, P. R. China
}

Received 2 November 2011; accepted in revised form 11 January 2012

\begin{abstract}
Terephthalate (TA) intercalated layered double hydroxides (LDHs) were synthesized using hydroxides as raw materials, and poly(ethylene terephthalate) (PET)/LDH nanocomposites with different contents of TA intercalated LDHs were prepared by in-situ polymerization. The structure, morphology and thermal property of PET/LDH nanocomposites were investigated. The TA intercalated LDHs were partially exfoliated and well dispersed in PET matrix. The PET/LDH nanocomposites exhibit enhanced thermal stability relative to pure PET, confirmed by the thermogravimetric analysis results. The results of differential scanning calorimetry suggest that LDH nanoparticles could effectively promote the nucleation and crystallization of PET.
\end{abstract}

Keywords: nanocomposites, poly(ethylene terephthalate), layered double hydroxides, in situ polymerization

\section{Introduction}

Layered double hydroxides (LDHs), known as a class of anionic clays, have attracted increasing interest due to their broad applications in areas such as catalysis, materials, medicine and environmental protection. LDHs can be represented by the general formula $\left[\mathrm{M}^{2+}{ }_{(1-\mathrm{x})} \mathrm{M}^{3+}{ }_{\mathrm{x}}(\mathrm{OH})_{2}\right]^{\mathrm{x}+} \cdot \mathrm{A}^{\mathrm{n}-}{ }_{\mathrm{x} / \mathrm{n}} \cdot z \mathrm{H}_{2} \mathrm{O}$, where the di- and trivalent cations $\left(\mathrm{M}^{2+}\right.$ and $\mathrm{M}^{3+}$, respectively) can be most metal ions. The value of $x$ may be varied over a wide range. $\mathrm{An}^{-}$is an exchangeable anion, which can be simple inorganic species, organic anions, heteropoly acid anions, polymers [1,2].

The polymer/LDH systems have been much less studied than the cationic clays due to the delamination difficulties of LDHs with the small gallery space and hydrophilic surface character [3]. However, the highly tunable properties, the anion exchange capacity have converted these materials into a new emerging class of layered crystals, which seems to be better suited for the preparation of multifunctional polymer/layered crystal nanocomposites. In recent years, study on the LDH nanocomposites with various polymers such as polyimide [4], epoxy [5], poly(ethylene terephthalate) (PET) [6], polyamide 6 [7], poly(butylene terephtahlate) [8], unsaturated polyester [9] and poly(vinyl alcohol) $[10,11]$, concerning physical properties and dispersion, has been widely reported. To apply anionic LDHs to nanocomposite system, preparation of organo-modified LDHs resulting in an increase in gallery spacing is very important because inorganic LDHs and organic polymer matrix are basically incompatible. In the past 20 years, many reports about the intercalation of organic anions into LDHs were discussed [12-17].

PET is a semicrystalline polyester with a high melting point and very good mechanical strength, due to the presence of the aromatic ring in the polymeric

\footnotetext{
${ }^{*}$ Corresponding author, e-mail: jiaoqz@bit.edu.cn
}

(c) BME-PT 
structure [18]. Recently, PET/organo-modified LDH nanocomposites have been reported and focused on their synthesis and properties. Lee and coworkers [18] prepared PET/LDH nanocomposites using anionic surfactants intercalated LDHs by a direct melt compounding method. Rives and coworkers prepared PET/LDH nanocomposites through a microwave [19] and mechanical grinding method [20]. Dodecylsulfate intercalated LDHs were used to enhance the compatibility between the PET polymer and the LDHs. Recently, Rives and coworkers [21] reported the preparation of PET/LDH nanocomposites using TA intercalated LDHs through a microwave heating route. It is found that the microwave process improves the dispersion and the thermal stability of nanocomposites due to the interaction of the microwave radiation.

However, in situ polymerization has become the main procedure for the preparation of nanocomposites due to its versatility and compatibility with reactive monomers [22], as well as permitting the control of the polymer and the composite structures. This method relies on the swelling of the organically modified LDHs by the monomer, followed by in situ polymerization initiated thermally or by addition of a suitable compound (catalyst) [19]. The chain growth in the LDH galleries accelerates exfoliation and nanocomposite formation [6]. In this work, PET/LDH nanocomposites were prepared by in situ polymerization. LDHs were organically modified using terephthalate (TA) as the interlamellar anion, to overcome the lack of compatibility between the polymer and LDHs containing purely inorganic anions. The chemical, thermal properties and morphology of the PET/LDH nanocomposites were studied.

\section{Experimental}

\subsection{Materials}

All the reagents were purchased from the Beijing YILI Fine Chemical Limited (Beijing, P.R. China) and used without further purification.

\subsection{Preparation of TA intercalated LDHs}

The preparation of TA intercalated LDHs followed a simple but efficient method that was newly developed in our laboratories $[23,24]$. The key feature of this method is a reaction of freshly generated hydroxides and terephthalic acid under a hydrother- mal condition. Compared to other methods, the terephthalate-intercalated LDHs synthesized using this method exhibit higher purity and higher crystallinity.

The freshly generated $\mathrm{Mg}(\mathrm{OH})_{2}$ and $\mathrm{Al}(\mathrm{OH})_{3}$ (molar ratio 2:1) were placed in $80 \mathrm{~mL}$ of deionized water. Terephthalic acid was added to the suspension with a vigorous stirring. Then the suspension was taken under a hydrothermal condition at $120^{\circ} \mathrm{C}$ for $10 \mathrm{~h}$. The product was collected after filtration by vacuum pumping and washed thoroughly with deionized water several times, and dried at $80^{\circ} \mathrm{C}$ overnight.

\subsection{Preparation of PET/LDH nanocomposites}

All the samples were prepared by a conventional 2 -step polycondensation $[6,25]$. In a typical procedure for the preparation of PET/LDH nanocomposites, TA intercalated LDHs were previously dispersed in ethylene glycol (EG, $1 \mathrm{~mol}$ ) using a sonicating homogenizer for $15 \mathrm{~min}$. The EG slurry containing TA intercalated LDHs was then mixed with dimethyl terephthalate (DMT) $(0.5 \mathrm{~mol})$ and $0.020 \mathrm{wt} \%$ (with respect to the DMT amount) of manganese acetate and magnesium acetate as catalyst. TA intercalated LDH contents were $0,0.5,1.0$, and $2.0 \mathrm{wt} \%$ with respect to the DMT amount. The ester interchange reaction was carried out at 190 $230^{\circ} \mathrm{C}$ with a continuous removal of byproduct (methanol). Polycondensation reaction was carried out at $280^{\circ} \mathrm{C}$ with ethylene glycol antimony catalyst at a pressure of 0.1 Torr for $2 \mathrm{~h}$. The as-synthesized nanocomposite samples were dried at vacuum oven for 1 day at $70^{\circ} \mathrm{C}$.

\subsection{Characterizations}

The crystal structures of samples were identified using a powder X-ray diffraction (XRD) on an X' Pert Pro MPD Powder X-Ray diffractometer (PANalytical, Almelo, Holland) with $\mathrm{Cu} \mathrm{K} \alpha$ radiation. FT-IR spectra were recorded on a Bruker Vector 22 instrument (Brucker AXS, GmbH, Germany) after 20 scans within $4000-400 \mathrm{~cm}^{-1}$ at a resolution of $2 \mathrm{~cm}^{-1}$. The sample was finely ground for $1 \mathrm{~min}$, combined with oven dried spectroscopic grade $\mathrm{KBr}$ and pressed into a disc. The Scanning electron microscopy (SEM) images were recorded by a S-4800 instrument (Hitachi, Tokyo, Japan) at $15 \mathrm{kV}$. The SEM micrographs were taken from a sample fractured surface which was broken in liquid nitro- 
gen and the morphology of the samples was observed on a JEM-1200EX (JEOL Ltd, Japan) transmission electron microscope (TEM) operated at $100 \mathrm{kV}$ with copper mounted holey carbon grids. Thermogravimetric analysis (TGA) was carried out on a TA instrument Q5000 thermobalance (TA instruments, New Castle, DE, USA) over the range of 50 to $650^{\circ} \mathrm{C}$ at a heating rate of $10^{\circ} \mathrm{C} \cdot \mathrm{min}^{-1}$ under air atmosphere $\left(50 \mathrm{~mL} \cdot \mathrm{min}^{-1}\right)$. The thermal properties of the nanocomposites were examined with a Shimadzu DSC-60 instrument (Shimadzu, Kyoto, Japan). To remove previous thermal history, all samples were first heated $300^{\circ} \mathrm{C}$ for $5 \mathrm{~min}$ and then cooling run was performed at a rate of $10^{\circ} \mathrm{C} / \mathrm{min}$. Then, second heating run was carried out at a rate of $10^{\circ} \mathrm{C} / \mathrm{min}$.

\section{Results and discussion}

\subsection{The structure and morphology of TA intercalated LDHs}

The XRD pattern of TA intercalated LDHs is shown in Figure 1. For comparison, that of the carbonate LDHs prepared by a coprecipitation reaction is also presented in Figure 1. The XRD patterns exhibit the characteristic reflections of LDH materials with a series of (001) peaks appearing as narrow symmetric lines at low angle corresponding to the basal spacing and higher order reflections. Compared to the carbonate LDHs, the basal spacing of the TA intercalated LDHs increases from 0.76 to $1.42 \mathrm{~nm}$, which suggests the terephthalate anions were successfully intercalated. Given that the thickness of the brucite-like layer of LDHs is $0.48 \mathrm{~nm}$ [1], the gallery height in the TA intercalated LDHs is $0.94 \mathrm{~nm}$. This data is same as the diameter of the long axis of terephthalate anion, which suggests a

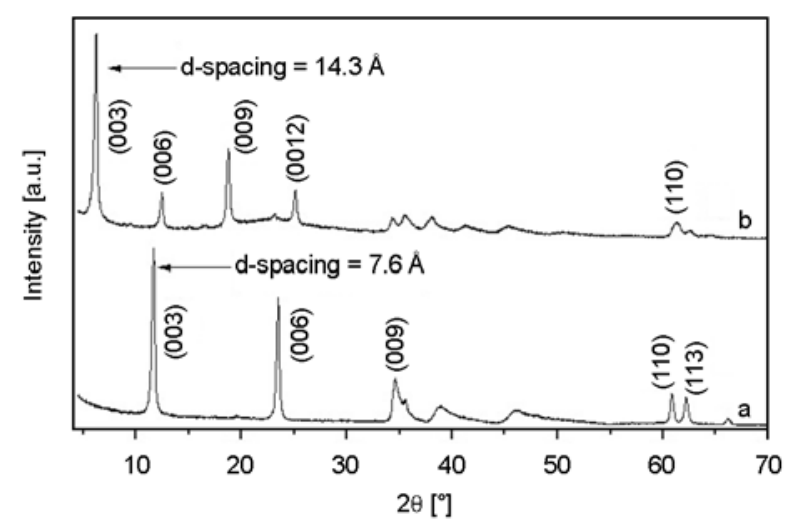

Figure 1. XRD patterns of different LDHs a) carbonate LDHs; b) TA intercalated LDHs

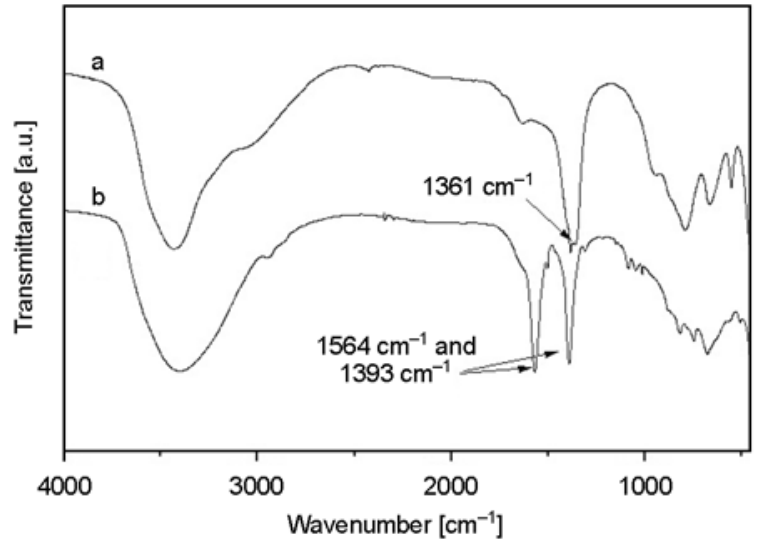

Figure 2. FT-IR spectra of different LDHs a) carbonate LDHs; b) TA intercalated LDHs

monolayer arrangement for the intercalated terephthalate anions oriented perpendicular to the $\mathrm{LDH}$ layers [26].

The FT-IR spectra of the carbonate LDHs and the TA intercalated LDHs are shown in Figure 2. The absorption at $1361 \mathrm{~cm}^{-1}$ which is attributed to carbonate ions in the carbonate LDHs is not present in the spectrum of the TA intercalated LDHs. The spectra of carboxylate are dominated by the asymmetric and symmetric $\mathrm{RCO}^{2-}$ stretches of the organic guests at around 1580 and $1400 \mathrm{~cm}^{-1}$ [27, 28]. As TA was incorporated into the LDH interlayers, two peaks appeared at 1564 and $1393 \mathrm{~cm}^{-1}$, which are assigned to carboxylate group stretching of the terephthalate guest [23]. This confirms the existence of terephthalate anion in the interlayer of LDH sheets.

\subsection{The structure and morphology of PET/LDH nanocomposites}

The XRD patterns for PET and PET/LDH nanocomposites with $0.5,1,2 \mathrm{wt} \%$ of TA intercalated LDHs and $2 \mathrm{wt} \%$ of carbonate LDHs are shown in Figure 3. In the case of PET nanocomposites with $2 \mathrm{wt} \%$ of carbonate LDHs, a small (003) reflection (arrow mark) which corresponds to a basal spacing of carbonate LDHs is shown at around $11.3^{\circ}$. It indicates that the carbonate LDH particles were not exfoliated by the PET molecules during in-situ polymerization. In the cases of PET nanocomposites with TA intercalated LDHs, the characteristic peak of basal spacing for TA intercalated LDHs completely disappeared, indicating the partial exfoliation of LDHs interlayer structures in the PET matrix, in which the gallery height of intercalated 


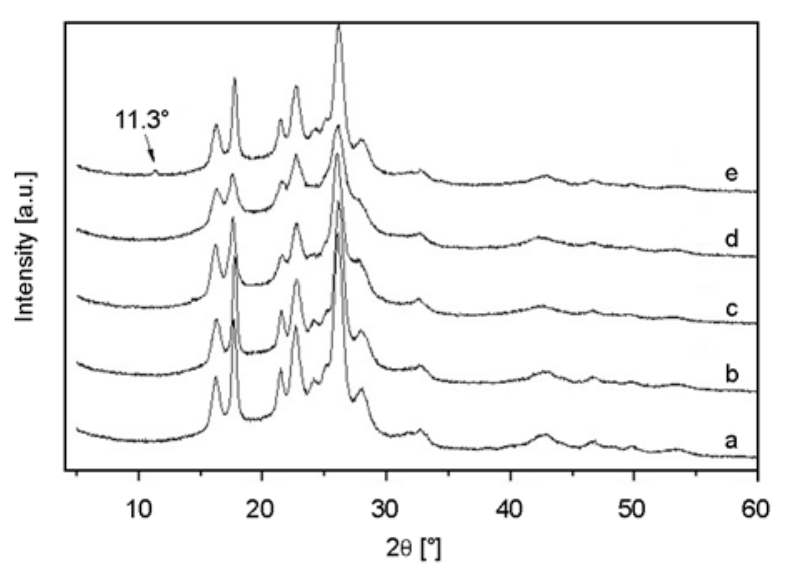

Figure 3. XRD patterns of PET (a) and PET/LDH nanocomposites with b) $0.5 \mathrm{wt} \%$ of TA intercalated LDHs; c) $1 \mathrm{wt} \%$ of TA intercalated LDHs; d) $2 \mathrm{wt} \%$ of TA intercalated LDHs; e) $2 \mathrm{wt} \%$ of carbonate LDHs

layers is large enough and the layer correlation is not detected by X-ray diffractometer. Although, XRD provides a partial picture about distribution of nanofiller and disappearance of peak corresponding to d-spacings does not always confirm the exfoliated nanocomposites [29], because XRD measure-

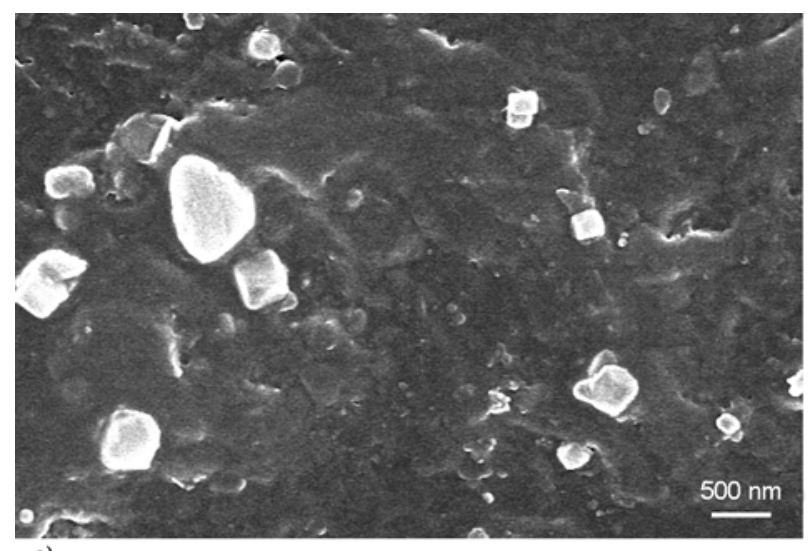

a)

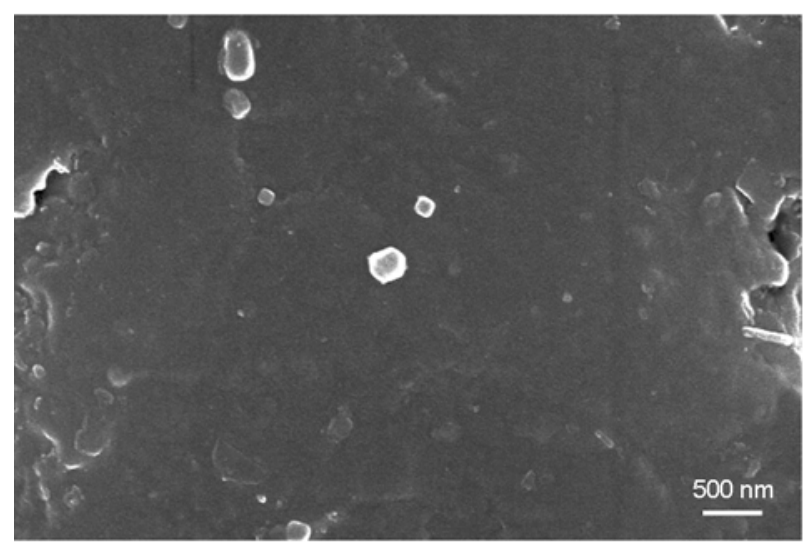

c) ments detect average diffractions came from overall sample area irradiated by X-ray. If the characteristic peak shift to the lower angle beyond the XRD scan range $\left(<3^{\circ}\right)$ owing to increased gallery spacing resulting from the partial intercalation of PET molecules, then LDH characteristic diffractions for the gallery spacing cannot be detected by the XRD apparatus [6]. Therefore, a complete characterization of nanocomposite morphology requires to be investigated [30,31].

The SEM images of PET nanocomposites with $2 \mathrm{wt} \%$ of carbonate LDHs and TA intercalated LDHs are shown in Figure 4. In Figure 4a, the particles of carbonate LDHs can be clearly seen. Some particles about $600 \mathrm{~nm}$ were shown, which were much bigger than the carbonate LDHs before polymerization. This is because the complete form of layered LDH aggregates. The carbonate LDHs had the least interaction with PET matrix, and were not intercalated by PET molecules during the polymerization. These layer structures can diffract the Xrays, resulting in the peak for $\mathrm{LDH}$ structure in XRD profiles which matches the XRD results

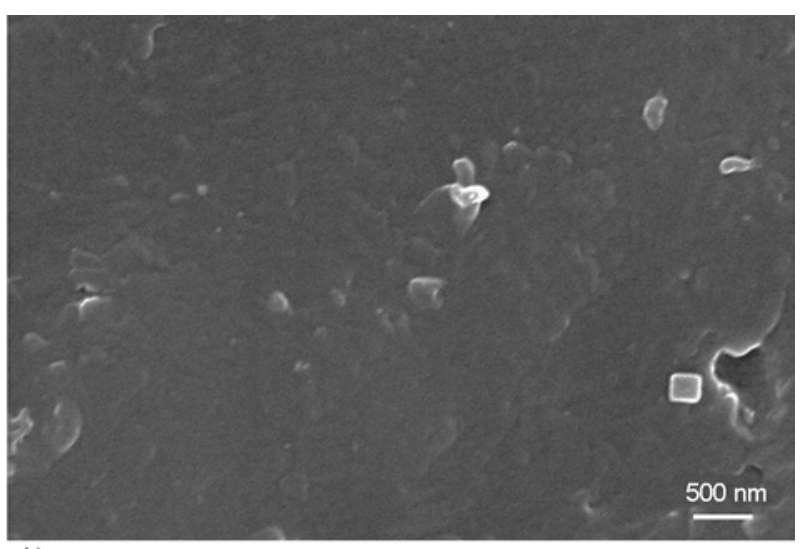

b)

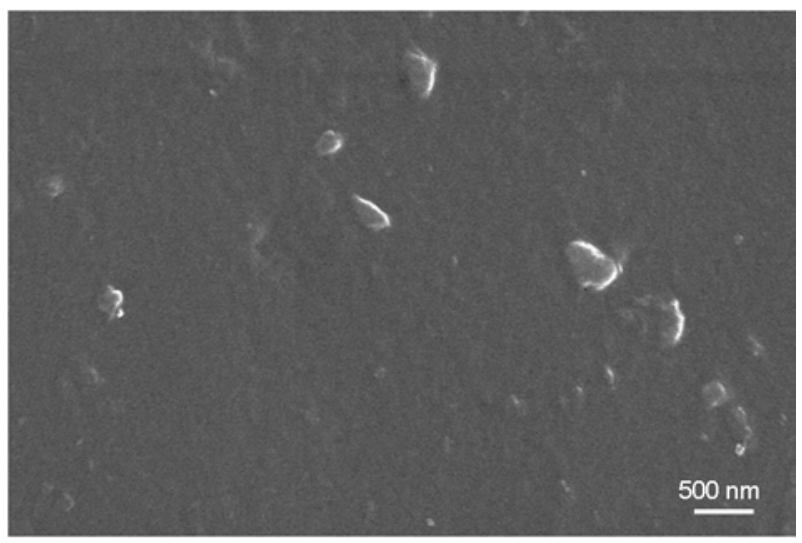

d)

Figure 4. SEM images of the PET/LDH nanocomposites with a) $2 \mathrm{wt} \%$ of carbonate LDHs; b) $0.5 \mathrm{wt} \%$ of TA intercalated LDHs; c) $1 \mathrm{wt} \%$ of TA intercalated LDHs; d) $2 \mathrm{wt} \%$ of TA intercalated LDHs 


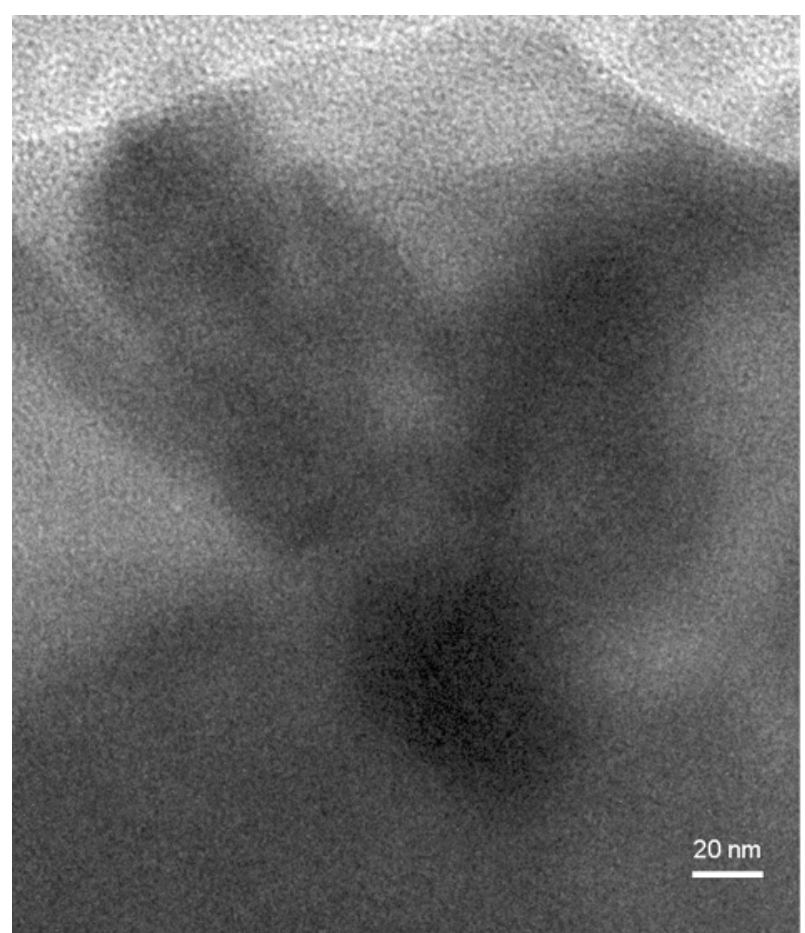

a)

Figure 5. TEM images of the PET/LDH nanocomposites with a) $2 \mathrm{wt} \%$ of carbonate LDHs; b) $2 \mathrm{wt} \%$ of TA intercalated LDHs

shown in Figure 3. In Figure $4 b, 4 c$ and $4 d$, there was little agglomeration of the particles. Apparently, the particles of TA intercalated LDHs were less than that of carbonate LDHs in PET matrix with the same loading level (2\%). It indicates that the TA intercalated LDHs were intercalated and/or exfoliated efficiently by PET molecules during polymerization and dispersed well in PET matrix. TEM was used to examine exactly the state of the TA intercalated LDHs in the PET matrix. The TEM images taken from PET nanocomposites with $2 \mathrm{wt} \%$ of carbonate LDHs and $2 \mathrm{wt} \%$ TA intercalated LDHs are shown in Figure 5. The dark lines represent the LDH layers, whereas the bright areas represent PET matrix. In Figure 5a, big particles or aggregates are found because the carbonate LDHs were not intercalated by PET molecules during the in-situ polymerization. In Figure 5b, the micrograph clearly shows the lamellar structure of LDHs exfoliated by the PET macromolecular chain; the lines of the layers are well shown using the arrow marks. The thickness and lateral sizes of the exfoliated LDH layers can be calculated as being about $1 \sim 2 \mathrm{~nm}$ and $20 \sim 80 \mathrm{~nm}$, respectively.

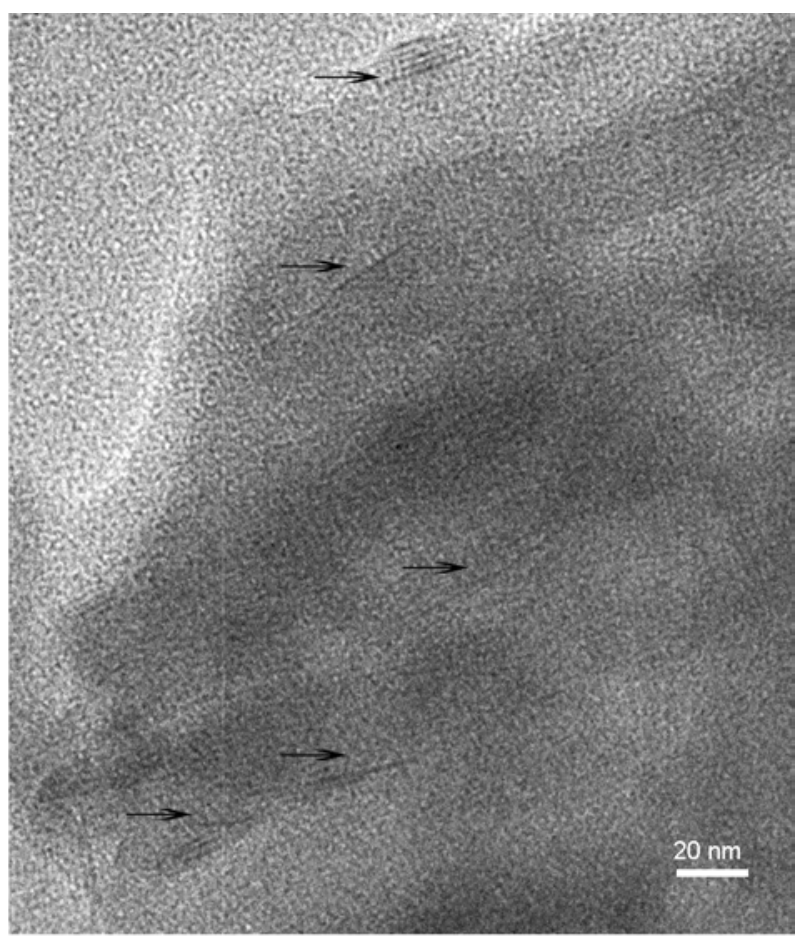

b)

\subsection{Thermal property and crystallization behavior of PET/LDH nanocomposites}

TGA curves for PET and PET/LDH nanocomposites with $0.5,1.0$, and $2.0 \mathrm{wt} \%$ of TA intercalated LDHs and $2 \mathrm{wt} \%$ of carbonate LDHs are shown in Figure 6, and the results are summarized in Table 1. Decomposition of PET takes place in three steps [19]. The first weight loss starts at about $300^{\circ} \mathrm{C}$, corresponds to removal of water. The main weight loss starts at about $400^{\circ} \mathrm{C}$. This second step is attrib-

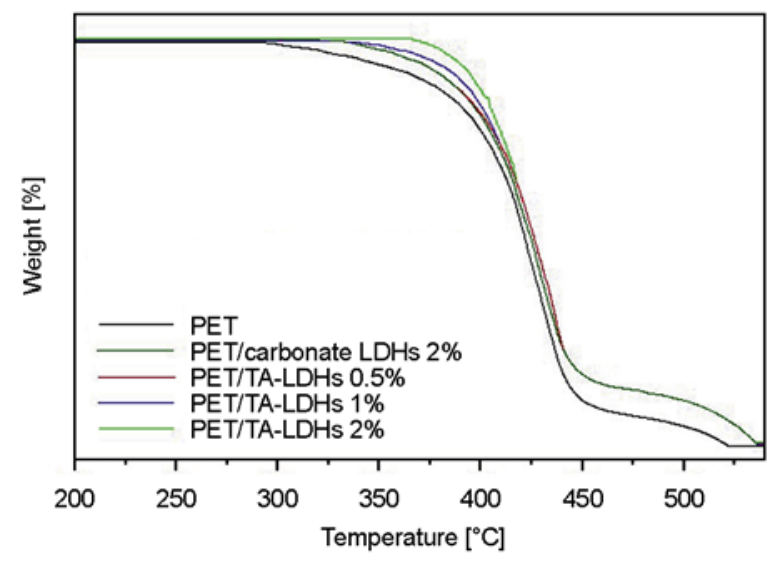

Figure 6. TGA curves of PET and PET/LDH nanocomposites with $2 \mathrm{wt} \%$ of carbonate LDHs and $0.5,1$, $2 \mathrm{wt} \%$ of TA intercalated LDHs 
uted to the partial decomposition of the polymer. Finally, a new weight loss, due to oxidative elimination of the carbonaceous residue derived from the initial polymer degradation, is recorded at $470^{\circ} \mathrm{C}$, and all the samples are finally lost at $520^{\circ} \mathrm{C}$. In Figure 6, all the nanocomposites are more stable up to high temperature than pure PET, and show similar curves and slopes. The temperature at weight reduction of $2 \%\left(\mathrm{~T}^{2}{ }_{\mathrm{D}}\right)$ and $5 \%\left(\mathrm{~T}^{5} \mathrm{D}\right)$ for PET/LDH nanocomposites in Table 1 are also higher than those of pure PET. It indicates that there is a strong interaction between the TA-LDHs and polymer matrix. The exfoliated nanolayers of TA-LDHs obstructed the internal diffusion of intense heat and various gaseous substances that formed during pyrolysis of PET. Terephthalate is used to increase the basal spacing of the LDHs and overcome the lack of compatibility between the polymer and LDHs containing purely inorganic anions. The increasing of the basal spacing of the LDHs is helpful for the exfoliation of LDH layers. After polymerization, the characteristic XRD peak of basal spacing for TA intercalated LDHs completely disappeared, indicating the partial exfoliation of LDHs interlayer structures. The SEM and TEM images can show that the TA intercalated LDHs were partially exfoliated and well dispersed in PET matrix during polymerization. Thus, it is believed that the introduction of TA intercalated LDHs into the PET matrix can improve the thermal stability owing to the heat insulation effect of the LDH layers and the mass transport barrier against the volatile gases generated during thermal decomposition [6]. The thermal stability of $\mathrm{PET} / \mathrm{LDHs}$ nanocomposites with $1 \%$ TA-LDHs is relatively higher than PET/LDHs nanocomposites with $2 \%$ TA-LDHs. This may be due to the dispersion of $1 \%$ TA-LDHs in the PET matrix is better than $2 \%$ according to the SEM images. The exfoliated nanolayers of PET/TA-LDHs $1 \%$ is more than that of $2 \%$.

PET is a semicrystalline polymer and its properties are related to its morphological features such as degree of crystallization, size (thickness and lateral dimension of lamellae) and perfection of crystallites [32]. Therefore, it is important to study the crystallization behavior of PET/LDH nanocomposites. Figures 7 and 8 are the differential scanning calorimetry (DSC) thermograms of pure PET and PET/LDH nanocomposites with $2 \mathrm{wt} \%$ of carbonate LDHs and $0.5,1,2 \mathrm{wt} \%$ of TA intercalated LDHs with the heating and cooling measurements, respectively. The results of DSC are summarized in Table 1 . The values of the melting peaks $\left(T_{\mathrm{m}}\right)$ of the

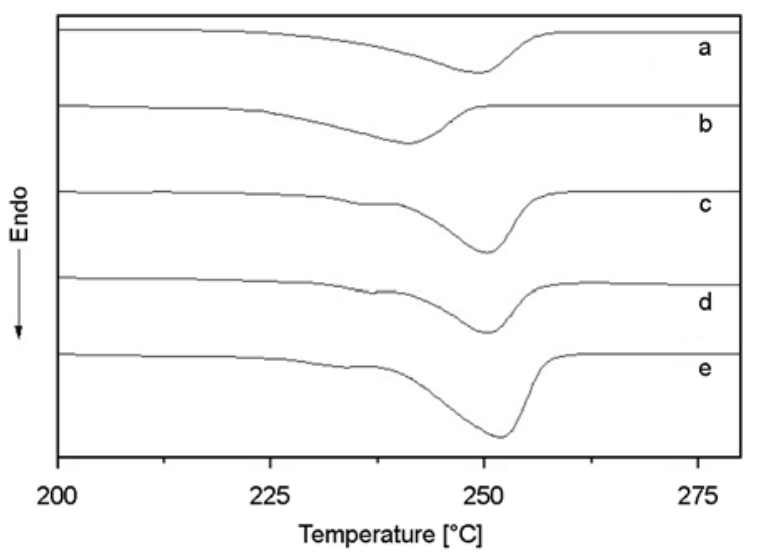

Figure 7. DSC thermograms of PET (a) and PET/LDH nanocomposites with $2 \mathrm{wt} \%$ of carbonate LDHs (b), 0.5 (c), 1 (d) and 2 (e) wt\% TA intercalated LDHs during heating run

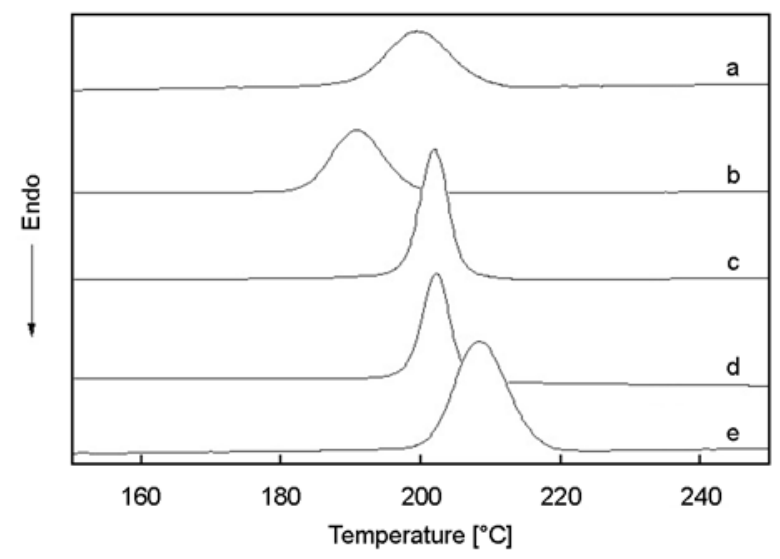

Figure 8. DSC thermograms of PET (a) and PET/LDH nanocomposites with $2 \mathrm{wt} \%$ of carbonate LDHs (b), 0.5 (c), 1 (d) and 2 (e) wt\% TA intercalated LDHs during cooling run

Table 1. Thermal properties of PET and PET/LDH nanocomposites

\begin{tabular}{|l|c|c|c|c|c|c|c|}
\hline \multicolumn{1}{|c|}{ Sample } & $\mathbf{T}_{\mathbf{m}}\left[{ }^{\circ} \mathbf{C}\right]$ & $\Delta \mathbf{H}_{\mathbf{0}}[\mathbf{J} / \mathbf{g}]$ & $\mathbf{X}_{\mathbf{c}}[\mathbf{\%}]$ & $\mathbf{T}_{\mathbf{c c}}\left[{ }^{\circ} \mathbf{C}\right]$ & $\Delta \mathbf{T}\left[{ }^{\circ} \mathbf{C}\right]$ & $\mathbf{T}^{2}{ }_{\mathbf{D}}\left[{ }^{\circ} \mathbf{C}\right]$ & $\left.\mathbf{T}^{\mathbf{5}}{ }_{\mathbf{D}}{ }^{\circ} \mathbf{C}\right]$ \\
\hline PET & 249.3 & 45.0 & 32 & 199.4 & 49.9 & 320 & 345 \\
\hline PET/carbonate LDHs 2\% & 241.0 & 38.6 & 28 & 190.7 & 50.3 & 349 & 368 \\
\hline PET/TA-LDHs 0.5\% & 250.2 & 53.4 & 38 & 201.9 & 48.3 & 329 & 358 \\
\hline PET/TA-LDHs 1\% & 250.3 & 50.0 & 36 & 202.2 & 48.1 & 377 & 386 \\
\hline PET/TA-LDHs 2\% & 251.8 & 72.7 & 53 & 208.3 & 43.5 & 354 & 374 \\
\hline
\end{tabular}


nanocomposites increased from 249.3 to $251.8^{\circ} \mathrm{C}$ when the TA intercalated LDH content was increased from 0 to $2 \mathrm{wt} \%$. The crystallization temperature during cooling $\left(T_{\mathrm{cc}}\right)$ of the nanocomposites increased from 199.4 to $208.3^{\circ} \mathrm{C}$ with increasing TA intercaltated LDH content. The crystallization temperature reflects the overall crystallization rate, attributed to the combined effects of nucleation and growth [33]. Thus the degree of super cooling $\left(\Delta T=T_{\mathrm{m}}-T_{\mathrm{cc}}\right)$ can be used to represent the crystallizability of the polymer; that is, the smaller the $\Delta T$, the higher the overall crystallization rate. As shown in Table 1, the degree of super cooling of the PET/TA intercalated LDH nanocomposites decreased.

The degree of crystallinity $\left(X_{\mathrm{c}}\right)$ of the samples were determined, which can be calculated using the Equation (1) [32]:

$X_{\mathrm{c}}=\frac{\Delta H_{\mathrm{f}}}{\Delta H_{\mathrm{f}}^{0}} \cdot 100$

where $\Delta H_{\mathrm{f}}^{0}$ is the melting enthalpy of $100 \%$ crystalline PET $\left(\Delta H_{\mathrm{f}}^{0}=140 \mathrm{~J} / \mathrm{g}\right.$ [34] $)$ and $\Delta H_{\mathrm{f}}$ is the normalized melting enthalpy of the sample, as shown by Equation (2):

$\Delta H_{\mathrm{f}}=\frac{\Delta H_{0}}{w}$

where $\Delta H_{0}$ is the heat of fusion of $\mathrm{PET} / \mathrm{LDH}$ nanocomposites $[\mathrm{J} / \mathrm{g}]$, and $w$ is the weight fraction of PET in the PET/LDH nanocomposite samples [wt $\%$.

As shown in Table 1, the $X_{\mathrm{c}}$ values of the PET/TALDH nanocomposites are all higher than those of pure PET. These results suggest that small additions of TA intercalated LDHs increased the crystallization degree of polymer. The LDH nanofillers acted as a nucleating agent for the crystallization and accelerated the crystallization rate of the PET matrix [18]. On the other hand, The $T_{\mathrm{m}}$ and $T_{\mathrm{cc}}$ values of PET nanocomposites with $2 \mathrm{wt} \%$ of carbonate LDHs were decreased. TA-LDHs can be partially exfoliated and well dispersed in PET due to the larger interlayer space and the stronger interaction with PET matrix. The exfoliated nanolayers effectively promote the nucleation and crystallization of PET. However, the carbonate LDHs had the least interaction with polymer matrix and did not have good compatibility with PET molecules. The carbonate LDHs were not exfoliated and agglomerated in the PET matrix. Therefore they cannot act as a nucleating agent of crystallization.

\section{Conclusions}

The PET/LDH nanocomposites were prepared by in-situ polymerization. Their structure, morphology, thermal property and crystallization behavior were investigated. To enhance the compatibility between PET matrix and LDHs, TA intercalated LDHs were prepared using hydroxides as raw materials. Compared to the agglomeration of carbonate LDHs in PET matrix, TA intercalated LDHs could be partially exfoliated by PET molecules during insitu polymerization and dispersed well in the PET matrix. The nanocomposites thus obtained were thermally more stable than pure PET. The addition of LDHs which acted as a nucleating agent resulted in an increase in crystallization rate.

\section{References}

[1] Cavani F., Trifirò F., Vaccari A.: Hydrotalcite-type anionic clays: Preparation, properties and applications. Catalysis Today, 11, 173-301 (1991).

DOI: 10.1016/0920-5861(91)80068-K

[2] Evans D. G., Xue D.: Preparation of layered double hydroxides and their applications as additives in polymers, as precursors to magnetic materials and in biology and medicine. Chemical Communications, 2006, 485-496 (2006).

DOI: $10.1039 / \mathrm{b} 510313 \mathrm{~b}$

[3] O'Leary S., O'Hare D., Seeley G.: Delamination of layered double hydroxides in polar monomers: New LDH-acrylate nanocomposites. Chemical Communications, 2002, 1506-1507 (2002).

DOI: $10.1039 / \mathrm{b} 204213 \mathrm{~d}$

[4] Hsueh H-B., Chen C-Y.: Preparation and properties of LDHs/polyimide nanocomposites. Polymer, 44, 11511161 (2003).

DOI: $10.1016 / \mathrm{S} 0032-3861(02) 00887-\mathrm{X}$

[5] Hsueh H-B., Chen C-Y.: Preparation and properties of LDHs/epoxy nanocomposites. Polymer, 44, 5275-5283 (2003). DOI: $10.1016 / \mathrm{S} 0032-3861(03) 00579-2$

[6] Lee W. D., Im S. S.: Thermomechanical properties and crystallization behavior of layered double hydroxide/ poly(ethylene terephthalate) nanocomposites prepared by in-situ polymerization. Journal of Polymer Science Part B: Polymer Physics, 45, 28-40 (2007).

DOI: $10.1002 /$ polb.20993 
[7] Zammarano M., Bellayer S., Gilman J. W., Franceschi M., Beyer F. L., Harris R. H., Meriani S.: Delamination of organo-modified layered double hydroxides in polyamide 6 by melt processing. Polymer, 47, 652-662 (2006).

DOI: $10.1016 /$ j.polymer.2005.11.080

[8] Berti C., Fiorini M., Sisti L.: Synthesis of poly(butylene terephtahlate) nanocomposites using anionic clays. European Polymer Journal, 45, 70-78 (2009).

DOI: 10.1016/j.eurpolymj.2008.09.039

[9] Pereira C. M. C., Herrero M., Labajos F. M., Marques A. T., Rives V.: Preparation and properties of new flame retardant unsaturated polyester nanocomposites based on layered double hydroxides. Polymer Degradation and Stability, 94, 939-946 (2009).

DOI: 10.1016/j.polymdegradstab.2009.03.009

[10] Li B., Hu Y., Zhang R., Chen Z., Fan W.: Preparation of the poly(vinyl alcohol)/layered double hydroxide nanocomposite. Materials Research Bulletin, 38, 1567-1572 (2003).

DOI: 10.1016/S0025-5408(03)00203-4

[11] Zhang Z., Zhu M., Sun B., Zhang Q., Yan C., Fang S.: The effect of hydrotalcite and zinc oxide on smoke suppression of commercial rigid PVC. Journal of Macromolecular Science Part A: Pure and Applied Chemistry, 43, 1807-1814 (2006).

DOI: $10.1080 / 10601320600940930$

[12] Meyn M., Beneke K., Lagaly G.: Anion-exchange reactions of layered double hydroxides. Inorganic Chemistry, 29, 5201-5207 (1990).

DOI: $10.1021 / \mathrm{ic} 00351 \mathrm{a} 013$

[13] Newman S. P., Jones W.: Synthesis, characterization and applications of layered double hydroxides containing organic guests. New Journal of Chemistry, 22, 105-115 (1998).

DOI: $10.1039 / \mathrm{a} 708319 \mathrm{j}$

[14] Kovanda F., Jindová E., Lang K., Kubát P., Sedláková Z.: Preparation of layered double hydroxides intercalated with organic anions and their application in LDH/ poly(butyl methacrylate) nanocomposites. Applied Clay Science, 48, 260-270 (2010).

DOI: 10.1016/j.clay.2009.11.012

[15] Káfuňková E., Taviot-Guého C., Bezdička P., Klementová M., Kovář P., Kubát P., Mosinger J., Pospíšil M., Lang K.: Porphyrins intercalated in $\mathrm{Zn} / \mathrm{Al}$ and $\mathrm{Mg} / \mathrm{Al}$ layered double hydroxides: Properties and structural arrangement. Chemistry of Materials, 22, 2481-2490 (2010).

DOI: $10.1021 / \mathrm{cm} 903125 \mathrm{v}$

[16] Costa F. R., Leuteritz A., Wagenknecht U., Jehnichen D., Häußler L., Heinrich G.: Intercalation of Mg-Al layered double hydroxide by anionic surfactants: Preparation and characterization. Applied Clay Science, 38, 153-164 (2008).

DOI: $10.1016 /$ j.clay.2007.03.006
[17] Gago S., Costa T., de Melo J. S., Gonçalves I. S., Pillinger M.: Preparation and photophysical characterisation of $\mathrm{Zn}-\mathrm{Al}$ layered double hydroxides intercalated by anionic pyrene derivatives. Journal of Materials Science, 18, 894-904 (2008).

DOI: $10.1039 / \mathrm{b} 715319 \mathrm{~h}$

[18] Lee W. D., Im S. S., Lim H-M., Kim K-J.: Preparation and properties of layered double hydroxide/poly(ethylene terephthalate) nanocomposites by direct melt compounding. Polymer, 47, 1364-1371 (2006).

DOI: $10.1016 /$ j.polymer.2005.12.056

[19] Martínez-Gallegos S., Herrero M., Rives V.: In situ microwave-assisted polymerization of polyethylene terephtalate in layered double hydroxides. Journal of Applied Polymer Science, 109, 1388-1394 (2008). DOI: 10.1002/app.28215

[20] Martínez-Gallegos S., Herrero M., Barriga C., Labajos F. M., Rives V.: Dispersion of layered double hydroxides in poly(ethylene terephthalate) by in situ polymerization and mechanical grinding. Applied Clay Science, 45, 44-49 (2009).

DOI: $10.1016 /$ j.clay.2009.04.007

[21] Herrero M., Martínez-Gallegos S., Labajos M., Rives V.: Layered double hydroxide/polyethylene terephthalate nanocomposites. Influence of the intercalated LDH anion and the type of polymerization heating method. Journal of Solid State Chemistry, 184, 2862-2869 (2011).

DOI: $10.1016 /$ j.jssc.2011.08.017

[22] Chang J-H., Mun M-K., Lee I. C.: Poly(ethylene terephthalate) nanocomposite fibers by in situ polymerization: The thermomechanical properties and morphology. Journal of Applied Polymer Science, 98, 2009-2016 (2005).

DOI: $10.1002 / \mathrm{app} .22382$

[23] Cui W., Jiao Q., Zhao Y., Zhou M.: Preparation of carboxylate-intercalated layered double hydroxides using mixed hydroxides or oxides. Micro and Nano Letters, 6, 832-835 (2011).

DOI: $10.1049 / \mathrm{mnl} .2011 .0323$

[24] Jiao Q., Cui W., Zhao Y.: A method for the preparation of organic acid anions intercalated layered double hydroxides. CN102009959A, P. R. China (2011).

[25] Chang J-H., Kim S. J., Joo Y. L., Im S.: Poly(ethylene terephthalate) nanocomposites by in situ interlayer polymerization: The thermo-mechanical properties and morphology of the hybrid fibers. Polymer, 45, 919-926 (2004).

DOI: $10.1016 /$ j.polymer.2003.11.037

[26] Newman S. P., Williams S. J., Coveney P. V., Jones W.: Interlayer arrangement of hydrated $\mathrm{MgAl}$ layered double hydroxides containing guest terephthalate anions: Comparison of simulation and measurement. Journal of Physical Chemistry B, 102, 6710-6719 (1998). DOI: $10.1021 / j p 981426 r$ 
[27] Prevot V., Forano C., Besse J. P.: Syntheses and thermal and chemical behaviors of tartrate and succinate intercalated $\mathrm{Zn}_{3} \mathrm{Al}$ and $\mathrm{Zn}_{2} \mathrm{Cr}$ layered double hydroxides. Inorganic Chemistry, 37, 4293-4301 (1998) DOI: $10.1021 /$ ic 9801239

[28] Zhang H., Zhang F., Ren L., Evans D. G., Duan X.: Synthesis of layered double hydroxide anionic clays intercalated by carboxylate anions. Materials Chemistry and Physics, 85, 207-214 (2004)

DOI: $10.1016 /$ j.matchemphys.2004.01.020

[29] Acharya H., Srivastava S. K., Bhowmick A. K.: Synthesis of partially exfoliated EPDM/LDH nanocomposites by solution intercalation: Structural characterization and properties. Composites Science and Technology, 67, 2807-2816 (2007).

DOI: 10.1016/j.compscitech.2007.01.030

[30] Morgan A. B., Gilman J. W.: Characterization of polymer-layered silicate (clay) nanocomposites by transmission electron microscopy and X-ray diffraction: A comparative study. Journal of Applied Polymer Science, 87, 1329-1338 (2003).

DOI: 10.1002/app.11884
[31] Yu Z-Z., Yang M. S., Zhang Q., Zhao C., Mai Y-W.: Dispersion and distribution of organically modified montmorillonite in nylon-66 matrix. Journal of Polymer Science Part B: Polymer Physics, 41, 1234-1243 (2003).

DOI: $10.1002 /$ polb.10480

[32] He J-P., Li H-M., Wang X-Y., Gao Y.: In situ preparation of poly(ethylene terephthalate)- $\mathrm{SiO}_{2}$ nanocomposites. European Polymer Journal, 42, 1128-1134 (2006).

DOI: $10.1016 /$ j.eurpolymj.2005.11.002

[33] Ou C. F., Ho M. T., Lin J. R.: Synthesis and characterization of poly(ethylene terephthalate) nanocomposites with organoclay. Journal of Applied Polymer Science, 91, 140-145 (2004). DOI: $10.1002 / a p p .13158$

[34] Jandali M. Z., Widmann G.: Application handbook of thermal analysis: Thermoplastics. Donghua University Press, Shanghai (2008). 